\title{
IPAL Komunal dalam Mengolah Limbah Rumah Tangga di Desa Dutohe Barat
}

\author{
Communal Wastewater Treatment in Household Waste Treatment in Dutohe Barat Village
}

Sulastri Pua Age*
Rahman Suleman
Indra Haryanto Ali
Department of Environmental
Sanitation, Poltekkes Kemenkes
Gorontalo, Gorontalo City,
Gorontalo, Indonesia
email: sulastripage@gmail.com
Kata Kunci
Pengolahan air limbah
Air limbah rumah tangga
Gorontalo
Keywords:
Waste water treatment
Household wastewater
Gorontalo

\begin{abstract}
Abstrak
Desa Dutohe Barat termasuk salah satu desa yang tergolong sebagai wilayah darurat sanitasi akibat limbah rumah tangga, yang berasal dari aktifitas kegiatan manusia baik dalam keperluan mandi, mencuci, dan memasak. Tujuan dari kegiatan ini adalah menuntaskan masalah pencemaran lingkungan melalui IPAL komunal yang didesain dan dibuat sesuai dengan standar yang berlaku. Sampel dalam kegiatan ini adalah limbah cair rumah tangga yang berasal dari 5 rumah yang ada di Dusun 4 Desa Dutohe Barat. Diperoleh data awal kualitas air limbah adalah BOD yang mulanya sebesar $265 \mathrm{mg} / \mathrm{l}$, COD sebesar $290 \mathrm{mg} / \mathrm{l}$, serta minyak dan lemak sebesar $27 \mathrm{mg} / \mathrm{l}$. Metode kegiatan dilakukan dengan 3 tahapan (observasi, sosialisasi dan evaluasi). Diperoleh hasil penurunan bahan pencemar limbah setelah melewati pengolahan dengan IPAL yaitu BOD turun menjadi $98 \mathrm{mg} / \mathrm{l}$, COD turun menjadi $90 \mathrm{mg} / \mathrm{l}$, serta minyak dan lemak turun menjadi $10 \mathrm{mg} / 1$. Selain itu, output dari hasil pengolahan IPAL ini digunakan petani untuk mengairi tanaman.
\end{abstract}

\begin{abstract}
The village of Dutohe Barat is classified as an emergency sanitation area due to household waste produced by human activities (bathing, washing, and cooking). This activity aims to solve the problem by designing and making the communal wastewater treatment that has been standardized. The sample is liquid waste collected from 5 houses in section 4. Initial data on wastewater quality were obtained were BOD, which initially was $265 \mathrm{mg} / \mathrm{l}$, COD was $290 \mathrm{mg} /$, and oil and fat were $27 \mathrm{mg} / \mathrm{l}$. The activity method is carried out in 3 stages (observation, socialization, and evaluation). After going through treatment with this communal wastewater treatment, the results of the reduction in waste pollutants were BOD decreased to $98 \mathrm{mg} / \mathrm{l}, \mathrm{COD}$ decreased to $90 \mathrm{mg} /$, and oil and fat decreased to 10 $\mathrm{mg} / \mathrm{l}$. In addition, the output from the wastewater treatment processing is used by farmers to irrigate crops.
\end{abstract}

(C) 2022 Sulastri Pua Age, Rahman Suleman, Indra Haryanto Ali. Published by Institute for Research and Community Services Universitas Muhammadiyah Palangkaraya. This is Open Access article under the CC-BYSA License (http://creativecommons.org/licenses/by-sa/4.0/). DOI: https://doi.org/10.33084/pengabdianmu.v7i1.2285

\section{PENDAHULUAN}

Limbah rumah tangga merupakan salah satu limbah yang masih menjadi perhatian global, dan proses pengolahannya terus mengalami perkembangan inovasi (U.S. Environmental Protection Agency, 2002; Ghawi, 2018; Khumaidi et al., 2019; Marliani, 2014). Di Indonesia, permasalahan limbah rumah tangga juga masih menjadi prioritas penanganan oleh pemerintah (Ermayda et al., 2019; Hasibuan, 2016; Junaedi \& Hasanah, 2014; Nilasari et al., 2016), hal ini karena limbah cair rumah tangga mempiunyai dampak negatif bagi lingkungan apabila tidak emlalui proses pengolahan (Dahruji et al., 2017). dibuktikan dalam program Sanitasi Total Berbasis Masyarakat (STBM).

Limbah cair rumah tangga yang dibuang langsung ke lingkungan tanpa mengalami proses pengolahan, dapat mencemari sumber baku air minum. Berdasarkan hasil survey dan observasi yang dilakukan oleh Dinas Kesehatan Bone Bolango (2013) yang tertuang dalam laporan buku sanitasi, Desa Dutohe Barat merupakan desa yang masuk dalam kategori darurat sanitasi, disebabkan oleh tingginya limbah pencemar yang berasal dari aktivitas rumah tangga. Sehingga kegiatan ini 
memberikan solusi berupa pembuatan IPAL komunal yang berfungsi menurukan konsentrasi pencemar pada limbah rumah tangga di Desa Dutohe Barat. Target luaran dari kegiatan ini adalah terolahnya limbah rumah tangga, sehingga pencemaran lingkungan akibat limbah rumah tangga di Desa Dutohe Barat dapat diminimalisir atau dikurangi, serta output pengolahan limbah dapat dimanfaatkan sebagai air bersih untuk pengairan tanaman masyarakat.

\section{METODE}

Dalam pembuatan IPAL komunal diperlukan beberapa alat yaitu sekop, cangkul, pompa air merk Sanyo, cetakan IPAL, besi, kuas, dan alat ukur pH air limbah model Pen KL-081. Bahan-bahan yang diperlukan dalam membuat IPAL komunal adalah semen merk Conch, pasir, kerikil, ijuk, cat merk Avian, dan air. Metode pengujian biochemical oxygen demand (BOD) mengacu pada SNI 06-6989.14-2004 dan SNI 6989.72-2009. Sementara untuk pengujian chemical oxygen demand (COD) yang digunakan mengacu pada SNI 06-6989.2-2004.

Kegiatan ini mempunyai beberapa tahapan yaitu:

1. Koordinasi

Pihak Poltekkes Kemenkes Gorontalo berkoordinasi dengan Dinas Kesehatan Bone Bolang, dalam hal ini diwakili oleh Puskesmas Kabila, untuk mendapatkan data mengenai daerah yang mempunyai masalah terkait limbah rumah tangga. Setelah diperoleh data dan informasi, selanjutnya pihak Poltekkes Kemenkes Gorontalo berkoordinasi dengan Pemerintah Desa Dutohe Barat selaku lokasi fokus kegiatan.

2. Sosialisasi

Poltekkes Kemenkes Gorontalo melakukan sosialisasi terkait bentuk kegiatan, serta penentuan lokasi untuk pembuatan IPAL komunal. Setelah berdiskusi dengan kepala Dusun di Dutohe Barat, diperoleh kesepakatan untuk membuat IPAL komunal di Dusun 4.

3. Identifikasi kadar BOD, COD, dan kandungan minyak tahap I

Tahapan ini dilakukan untuk memperoleh data awal mengenai kandungan BOD, COD, dan kandungan minyak dalam limbah cair rumah tangga yang berasal dari 5 rumah di Dusun 4, Desa Dutohe Barat, sebelum dilakukan pengolahan dengan IPAL komunal.

4. Pembuatan IPAL komunal

Selanjutnya pihak Poltekkes Kemenkes Gorontalo melakukan eksekusi pembangunan IPAL komunal di Dusun 4, Desa Dutohe Barat dengan alat dan bahan yang telah disediakan. Dalam tahapan pembuatan IPAL komunal, Poltekkes Kemenkes Gorontalo memberdayakan masyarakat sekitar yang berprofesi sebagai tukang.

5. Peresmian

IPAL yang telah dibangun, selanjutnya diresmikan oleh Kepala Desa Dutohe Barat, sebelum digunakan oleh masyarakat.

6. Identifikasi kadar BOD, COD, dan kandungan minyak tahap II

Tahapan ini dilakukan untuk memperoleh data awal mengenai kandungan BOD, COD, dan kandungan minyak dalam limbah cair rumah tangga yang berasal dari 5 rumah di Dusun 4, Desa Dutohe Barat, setelah dilakukan pengolahan dengan IPAL komunal.

\section{HASIL DAN PEMBAHASAN}

Kegiatan pembuatan IPAL komunal terbukti sangat efektif dalam menurunkan konsentrasi bahan pencemar (BOD, COD, serta kandungan minyak dan lemak) yang ada dalam limbar cair rumah tangga, sehingga kegiatan ini mendapatkan sambutan yang sangat baik dari masyarakat dan pihak Pemerintah Desa Dutohe Barat. IPAL komunal yang dibangun dalam kegiatan ini, terbukti sangat efektif dalam menurunkan konsentrasi bahan pencemar dalam limbah rumah tangga. Hal ini dapat dilihat pada Tabel I dan II, sedangkan dokumentasi kegiatan disajikan pada Gambar 1 sampai 5. 
Tabel I. Besaran konsentrasi bahan pencemar pada limbah rumah tangga sebelum diolah

\begin{tabular}{lccc}
\hline $\begin{array}{c}\text { Indikator Bahan } \\
\text { Pencemar }\end{array}$ & Konsentrasi Bahan Pencemar & Keterangan & Standar baku mutu \\
\hline $\mathrm{pH}$ & 8 & Memenuhi syarat & Peraturan Menteri Lingkungan \\
BOD & $265 \mathrm{mg} / 1$ & Tidak memenuhi syarat & Hidup Republik Indonesia \\
COD & $290 \mathrm{mg} / 1$ & Tidak memenuhi syarat & Nomor 5 tahun 2014 Tentang \\
Minyak dan Lemak & $27 \mathrm{mg} / 1$ & Tidak memenuhi syarat & Baku mutu air limbah \\
\hline
\end{tabular}

Tabel II. Besaran konsentrasi bahan pencemar pada limbah rumah tangga setelah diolah

\begin{tabular}{lccc}
\hline $\begin{array}{c}\text { Indikator Bahan } \\
\text { Pencemar }\end{array}$ & Konsentrasi Bahan Pencemar & Keterangan & Standar baku mutu \\
\hline pH & 7 & Memenuhi syarat & Peraturan Menteri Lingkungan \\
BOD & $98 \mathrm{mg} / 1$ & Memenuhi syarat & Hidup Republik Indonesia \\
COD & $90 \mathrm{mg} / 1$ & Memenuhi syarat & Nomor 5 tahun 2014 Tentang \\
Minyak dan Lemak & $10 \mathrm{mg} / 1$ & Memenuhi syarat & Baku mutu air limbah \\
\hline
\end{tabular}

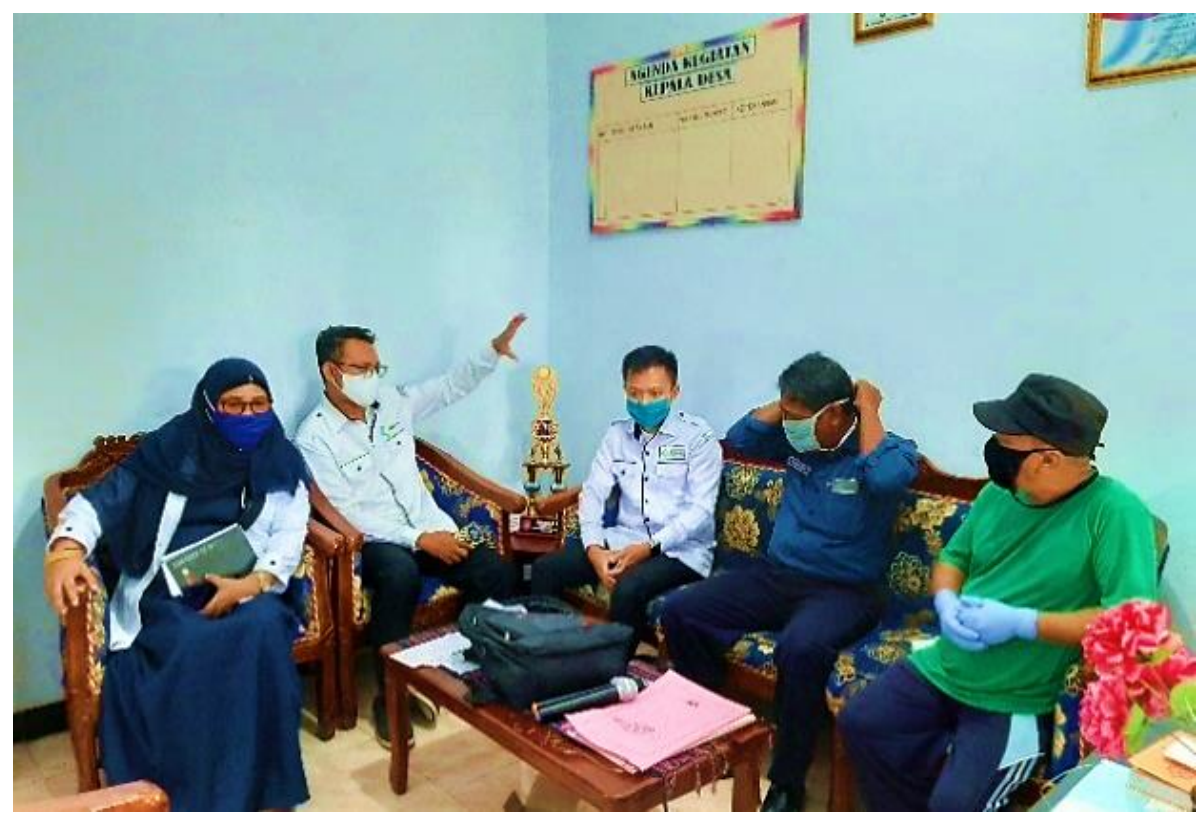

Gambar 1. Koordinasi dengan Pemerintah Desa Dutohe Barat

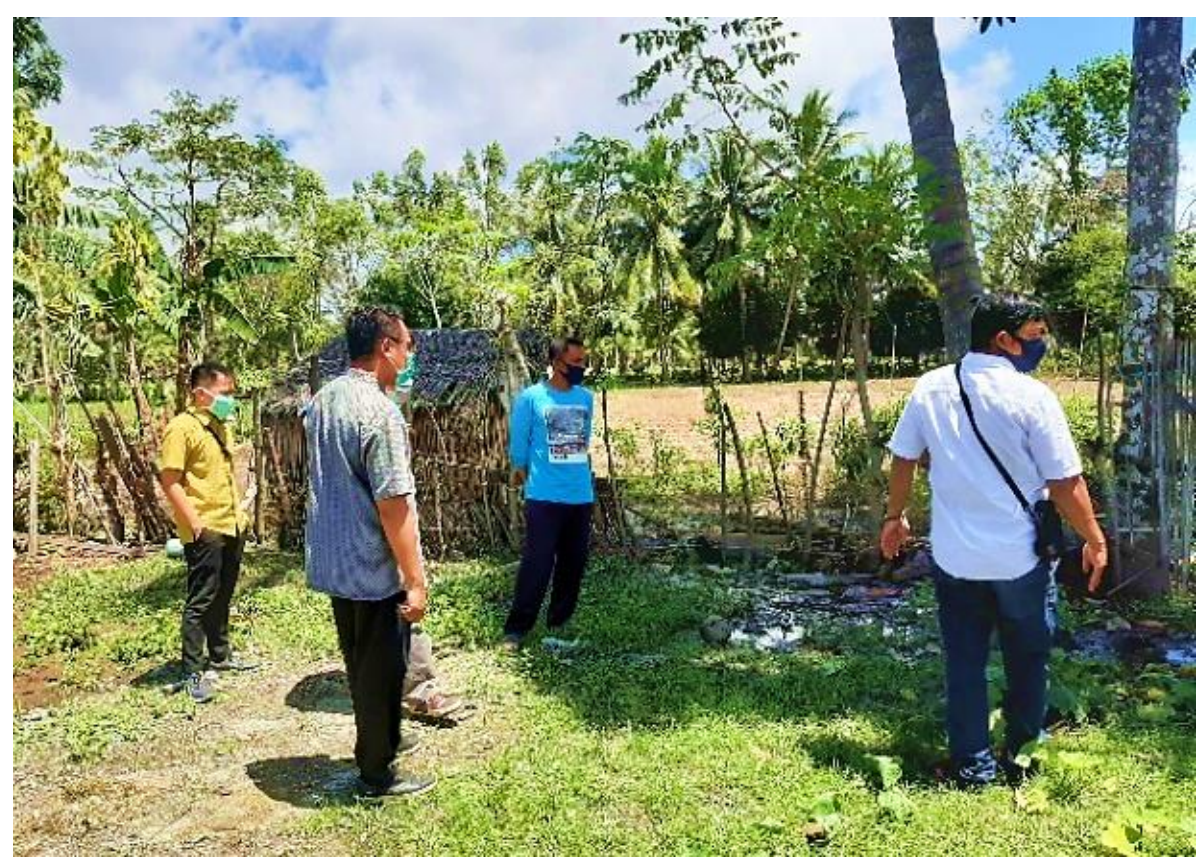

Gambar 2. Survey lokasi pembuatan IPAL 


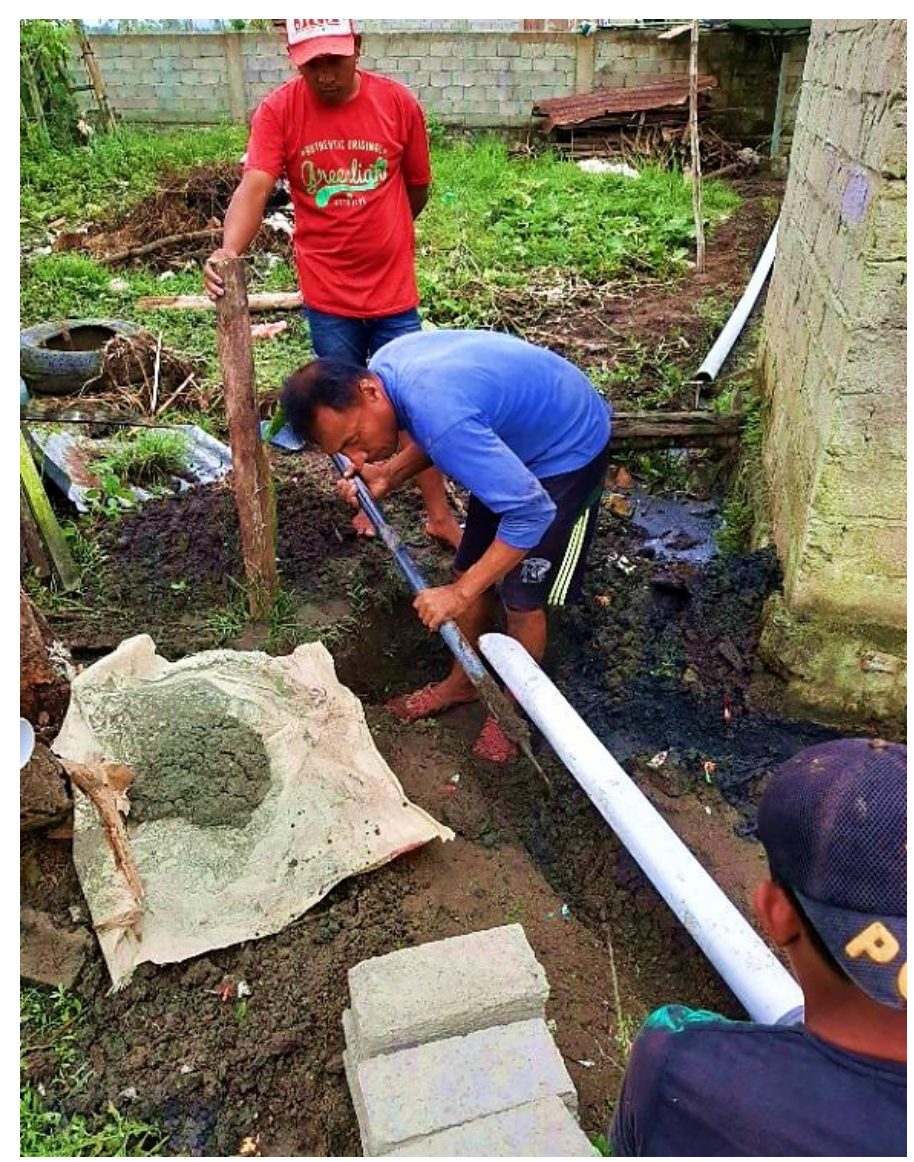

Gambar 3. Proses pembuatan IPAL

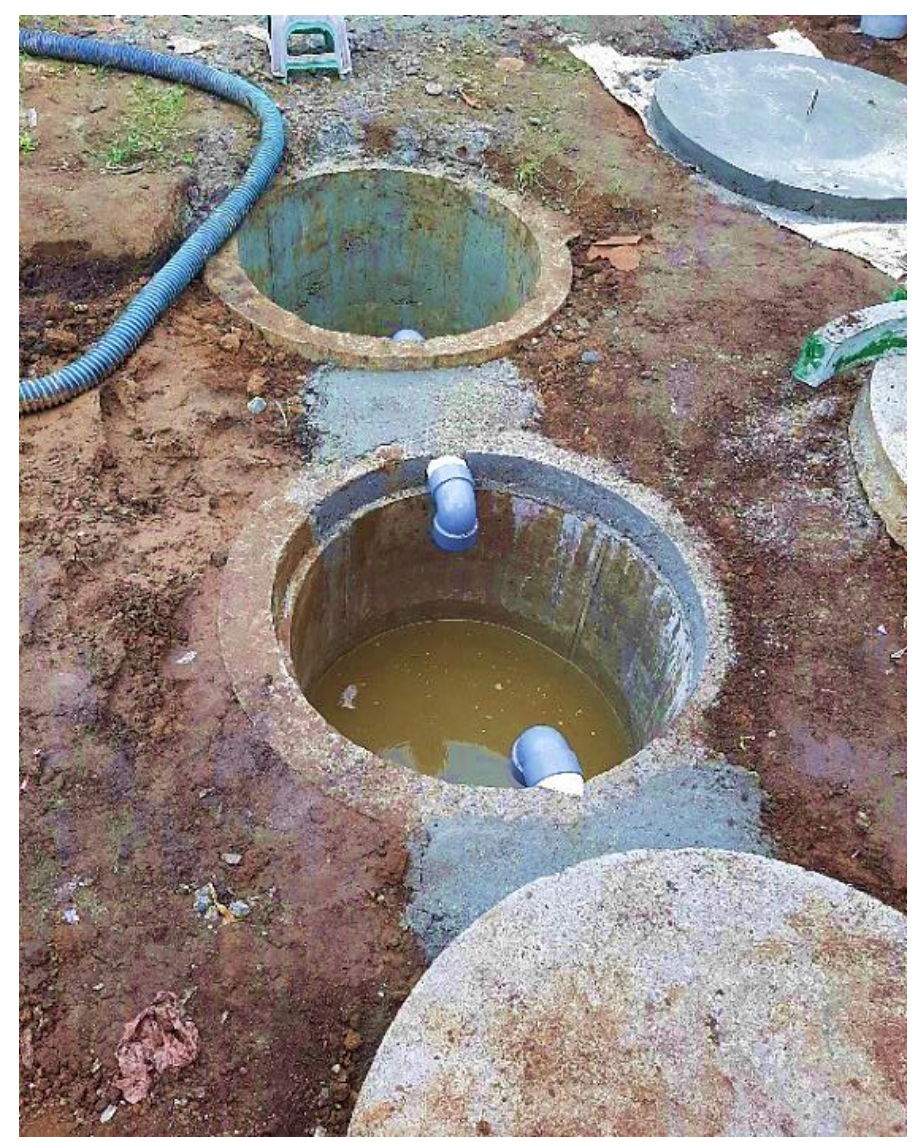

Gambar 4. IPAL komunal 


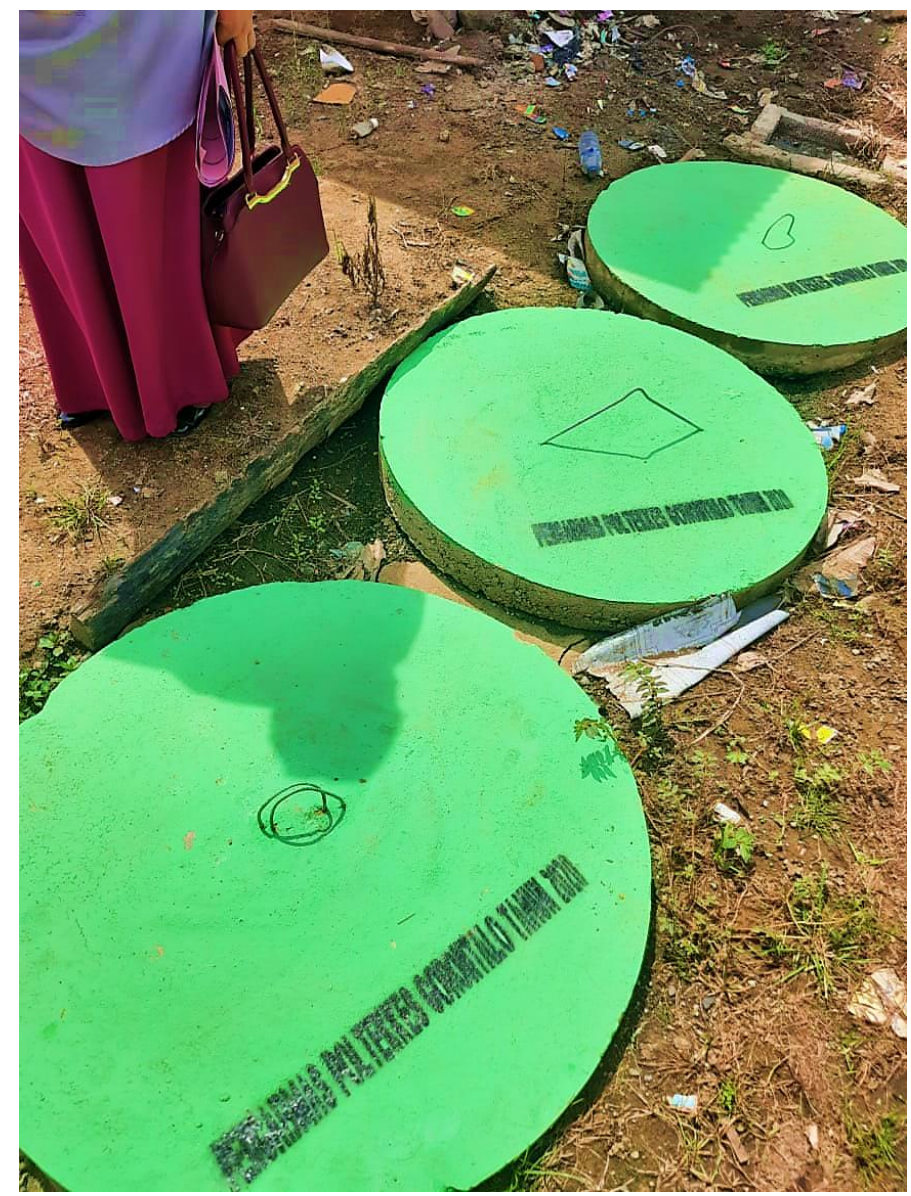

Gambar 5. Hasil akhir pembuatan IPAL

\section{KESIMPULAN}

IPAL komunal yang dibangun di Desa Dutohe Barat, Kecamatan Kabila, Kabupaten Bone Bolango, terbukti cukup efektif dalam menurunkan konsentrasi bahan pencemar. Diperoleh data awal kualitas air limbah adalah BOD yang mulanya sebesar $265 \mathrm{mg} / \mathrm{l}$, COD sebesar $290 \mathrm{mg} / \mathrm{l}$, serta minyak dan lemak sebesar $27 \mathrm{mg} / \mathrm{l}$. Metode kegiatan dilakukan dengan 3 tahapan (observasi, sosialisasi dan evaluasi). Diperoleh hasil penurunan bahan pencemar limbah setelah melewati pengolahan dengan IPAL yaitu BOD turun menjadi $98 \mathrm{mg} / \mathrm{l}$, COD turun menjadi $90 \mathrm{mg} / \mathrm{l}$, serta minyak dan lemak turun menjadi $10 \mathrm{mg} / 1$. Selain itu, output dari hasil pengolahan IPAL ini digunakan petani untuk mengairi tanaman.

\section{UCAPAN TERIMA KASIH}

Tim Pengabmas Poltekkes Kemenkes Gorontalo mengucapkan terima kasih yang setinggi tingginya kepada pihak yang telah membantu sehingga kegiatan ini dapat terlaksana yaitu pihak Dinas Kesehatan Bone Bolango, Puskesmas Kabila, Pemerintah Desa Dutohe Barat, Laboratorium UPT Dinas Kesehatan Kabupaten Gorontalo, dan Unit PPM Poltekkes Kemenkes Gorontalo.

\section{REFERENSI}

Dahruji, Wilianarti, P.F., Hendarto, T. 2017. Studi Pengolahan Limbah Usaha Mandiri Rumah Tangga dan Dampak Bagi Kesehatan di Wilayah Kenjeran. Aksiologiya : Jurnal Pengabdian Kepada Masyarakat. 1(1):36-44. http://dx.doi.org/10.30651/aks.v1i1.304 
Dinas Kesehatan Bone Bolango. 2013. Laporan Sanitasi Dasar. Gorontalo: Dinas Kesehatan Bone Bolango

Ermayda, R.Z., Nanda, H.I., Fatikhah, D.N. 2019. Mengolah Limbah Rumah Tangga untuk Meningkatkan Konsumsi Mandiri. Jurnal Karinov. 2(1):39-46. http:/ / dx.doi.org/10.17977/um045v2i1p39-46

Ghawi, A.H. 2018. Study on the development of household wastewater treatment unit. Journal of Ecological Engineering. 19(2):63-71. https://doi.org/10.12911/22998993/81780

Hasibuan, R. 2016. Analisis Dampak Limbah/Sampah Rumah Tangga Terhadap Pencemaran Lingkungan Hidup. Jurnal Ilmiah Advokasi. 4(1):42-52. https://doi.org/10.36987/jiad.v4i1.354

Junaedi, A., Hasanah, U.A. 2014. Penyuluhan tentang penanganan limbah rumah tangga. AJIE (Asian Journal of Innovation and Entrepreneurship). 3(2):111-114

Khumaidi, A., Rahayu, T., Darmiyanti, L. 2019. Sosialisasi Penanganan Air Limbah Rumah Tangga Di Karawang. Jurnal Solma. 8(2):287-294. https:/ / doi.org/10.29405/solma.v8i2.3165

Marliani, N. 2014. Pemanfaatan Limbah Rumah Tangga (Sampah Anorganik) Sebagai Bentuk Implementasi dari Pendidikan Lingkungan Hidup. Formatif : Jurnal Ilmiah Pendidikan MIPA. 4(2):124-132. http://dx.doi.org/10.30998/formatif.v4i2.146

Nilasari, E., Faizal, M., Suheryanto, S. 2016. Pengolahan Air Limbah Rumah Tangga dengan Menggunakan Proses Gabungan Saringan Bertingkat dan Bioremediasi Eceng Gondok (Eichornia crassipes), (Studi Kasus di perumahan Griya Mitra 2, Palembang). Jurnal Penelitian Sains. 18(1):8-13. https:/ / doi.org/10.26554/jps.v18i1.34

U.S. Environmental Protection Agency. 2002. Onsite Wastewater Treatment Systems Manual. https://www.epa.gov/sites/default/files/2015-06/documents/2004_07_07_septics_septic_2002_osdm_all.pdf 